Lentera Pustaka 3 (2): 153-163, 2017

Copyright (C2017, ISSN: 2302-4666 print/ 2540-9638 online

Available Online at: http://ejournal.undip.ac.id/index.php/lpustaka

\title{
PENGEMBANGAN PROFESIONALISME PUSTAKAWAN MELALUI PENDEKATAN ETIKA MORAL
}

\author{
Rahmat Setiawan Saefullah $^{1 *}$, Haryanto ${ }^{2}$ \\ 1,2D3 Perpustakaan, Fakultas Ilmu Sosial dan Politik, Universitas Sebelas Maret \\ Jl. Ir. Sutami No.36A, Jebres, Kota Surakarta, Jawa Tengah 57126 \\ *) Korespondensi: rahmatsetiawans@ @staff.uns.ac.id
}

\begin{abstract}
[Title: Developing librarians professionalism through ethic/morale approach] The librarian is one of the profession which one of his main duty is to serve the visitor or the book collector. The form of service to the user expects the librarian to be able to perform professionally. The professional job but in accordances with the completeness of facilities and right that must be earned, it will disrupt the librarian's job. Therefore, this exposure will try to describe the development of librarian professionalism through ethics and morals that exist in the ethical duties of the proffesion librarian. The aims of this paper is to know how improve the professionalism of librarians through ethical moral approach with socialisation and internalitation of libraian code ethics and the improvement of moral or marality from librarian. The result of this paper among others ethical behavior will be able to improve service. meanwhile, moral behavior contributes to the development of the proffesion.
\end{abstract}

Keywords: librarian; professionalism; ethics; moral

\begin{abstract}
Abstrak
Pustakawan merupakan salah satu profesi yang salah satu tugas pokoknya adalah melayani pengunjung atau peminjam koleksi. Bentuk pelayanan terhadap pengguna mengharapkan pustakawan untuk dapat bertugas secara profesional. Tuntutan kerja secara profesional namun apabila tidak diimbangi dengan segenap fasilitas serta hak yang wajib didapatkan, maka akan mengganggu tugas pustakawan itu. Oleh sebab itu, paparan ini akan mencoba mendeskripsikan pengembangan profesionalisme pustakawan melalui etika dan moral yang ada dalam tugas etik profesi pustakawan. Fokus pembahasan dalam tulisan ini adalah bagaimana meningkatkan profesionalisme pustakawan melaui pendekatan etika moral dengan sosialisasi dan internalisasi kode etik pustakawan, serta peningkatan moral atau moralita pustakawasan. Hasil dari paparan ini antara lain, perilaku etis akan dapat meningkatkan pelayanan. Sementara itu, perilaku moral berkontribusi pada pengembangan profesi.
\end{abstract}

Kata kunci: pustakawan; profesionalisme; etika; moral

\section{Pendahuluan}

Saat kita mempelajari sejarah perpustakaan dan pustakawan, maka kita mengetahui bahwa pustakawan merupakan profesi yang sangat luhur, dan tidak sedikit di antara mereka yang mendapatkan hak istimewa dari Raja. Pustakawan dianggap mempunyai kontribusi yang besar terhadap eksistensi sebuah negara atau kerajaan. Bahkan sekarangpun di banyak negara maju (Amerika dan Eropa), profesi pustakawan sangat dihargai dan dihormati. Hanya di negara-negara berkembang profesi pustakawan kurang begitu mendapat tempat. Meskipun sekarang kondisinya sudah berbeda, namun belum terjadi perubahan pengakuanyang signifikan.

Secara akademik fungsi utama diselenggarakannya perpustakaan, baik perpustakaan pendidikan maupun perpustakaan umum sudah sangat jelas yaitu untuk mendukung dan memfasilitasi pengembangan dan atau peningkatan derajat intelektual sivitas akademika (untuk perpustakaan pendidikan) maupun 
warga masyarakat secara umum (untuk perpustakaan umum). Namun demikian, masih banyak kita temukan, kalau tidak boleh mengatakan sebagian besar, fungsi dan kemanfaatan perpustakaan masih kurang sesuai dengan besaran investasi yang sudah dikeluarkan.

Kita sekalian meyakini bahwa perpustakaan merupakan sumber ilmu pengetahuan dan atau informasi, bahkan ada yang menyebutnya sebagai "jendela dunia". Keyakinan tersebut benar adanya. Tetapi anehnya, keyakinan tersebut tidak dibarengi dengan tindakan nyata untuk memperlakukan perpustakaan paralel dengan keyakinan tersebut. Bagi sebagian orang mungkin benar, tetapi bagi sebagian besar orang lainnya, utamanya di negara berkembang, hal ini masih diragukan.Perpustakaan perguruan tinggi, misalnya, yang notabene merupakan pusat penggodogan (pembinaan) calon ilmuwan, pemikir, birokrat, angka kunjungan civitas akademika ke perpustakaan masih relatif rendah.

Sebagian pengunjung mengatakan "tidak ke perpustakaan karena koleksi dan fasilitasnya terbatas atau kurang memadai". Sementara itu, Pustakawan mengatakan "tidak mampu memberikan layanan yang lebih baik" karena tidak tersedia anggaran yang cukup. Pada sisi lain, pemerintah, pejabat, anggota masyarakat dan para pemerhati perpustakaan yang lain, yang diharapkan mampu dan bersedia memberikan dukungan dan bantuan bagi pengembangan perpustakaan sebagai pusat informasi, masih sebatas sebagai orasi belaka atau lips service. Celakanya lagi, image sebagian besar anggota masyarakat (termasuk pejabat pemerintah) terhadap perpustakaan dan profesi pustakawan masih belum seperti yang diharapkan.

Lebih memprihatinkan lagi kalau kita melihat kondisi perpustakaan umum atau perpustakaan daerah. Angka kunjungannya masih sangat rendah. Tidak sebanding dengan investasi yang dialokasikan untuk membangun gedung, menyiapkan fasilitas, maupun untuk mengembangkan koleksi. Dalam kaitannya dengan persoalan ini, terdapat mata rantai lingkaran yang sangat sulit untuk diputuskan. Warga masyarakat enggan berkunjung ke perpustakaan disebabkan karena koleksinya tidak lengkap, karena fasilitasnya tidak nyaman, layanannya kurang menyenangkan, ruangannya panas dan sebagainya. Pustakawan tidak mampu memberikan layanan yang lebih baik karena budget-nya tidak memadai, karena kecewa merasa terbuang, karena merasa kurang dihargai harkat dan martabatnya. Sementara itu, pemerintah belum memberikan prioritas bagi pengembangan perpustakaan karena merasa belum perlu, karena angka kunjungan warga masyarakat tidak signifikan. Fakta ini, kemudian, diterjemahkan sebagai kesadaran masyarakat akan arti dan fungsi perpustakaan masih sangat rendah sehingga alokasi dana utuk pembangunan dan pengembangan bisa ditunda untuk membiayai program lain yang dianggap lebih penting.

Menghadapi kenyataan tersebut diperlukan "gergaji" yang sangat tajam untuk memutus mata rantai yang ada. Paper ini akan memberikan wacana bagaimana meningkatkan intelektualitas stakeholders atau warga masyarakat" dengan pokok kajian "peningkatan profesionalisme pustakawan melalui pendekatan etika-moral”. Du Mont (1991) berkaitan dengan tahapan perkembangan manajemen perpustakaan yang berkaitan dengan etika perpustakaan, sebagai berikut: 
Tabel 1. Du Mont (1991)

\begin{tabular}{|l|l|l|l|}
\hline & Stage 1 & Stage 2 & Stage 3 \\
\hline Ethical attitude & $\begin{array}{l}\text { Traditional (before } \\
1930 s\end{array}$ & $\begin{array}{l}\text { Stakeholders (1930 } \\
\text { 1950s: staff, patron }\end{array}$ & $\begin{array}{l}\text { Affirmative action } \\
(1960 s-\text { present })\end{array}$ \\
\hline Orientation & $\begin{array}{l}\text { Institutional self- } \\
\text { interest }\end{array}$ & $\begin{array}{l}\text { Institutional interest, } \\
\text { stake-holder interest }\end{array}$ & $\begin{array}{l}\text { Enlightened, self } \\
\text { interest, stake holder } \\
\text { interest, societal } \\
\text { interest }\end{array}$ \\
\hline Social values & $\begin{array}{l}\text { Personal and user } \\
\text { problems must be left } \\
\text { at home }\end{array}$ & $\begin{array}{l}\text { Employee have needs } \\
\text { beyond economics } \\
\text { needs and users have } \\
\text { needs beyond } \\
\text { information needs }\end{array}$ & $\begin{array}{l}\text { Societal interest and } \\
\text { participation is } \\
\text { fundamental to our } \\
\text { success }\end{array}$ \\
& $\begin{array}{l}\text { No government in- } \\
\text { volvement desired }\end{array}$ & $\begin{array}{l}\text { Government support is } \\
\text { a necessary evil }\end{array}$ & $\begin{array}{l}\text { Government and } \\
\text { information agencies } \\
\text { must cooperate to deal } \\
\text { with societal problems }\end{array}$ \\
\hline Political & & &
\end{tabular}

Kalau kita evaluasi, secara umum, dengan bantuan model Du Mont tersebut di atas, nampaknya perpustakaan kita masih beradapada level 2, itupun mungkin masih pada tahap-tahap awal. Kondisi ini nampaknya hanya berlaku untuk perpustakaan perguruan tinggi. Sedangkan untuk perpustakaan umum kelihatannya baru sedang merangkak menuju ke tahap ke-2. Ini mengandung makna bahwa kondisi perpustakaan kita, baik perpustakaan pendidikan maupun perpustakaan umum masih perlu dikembangkan lebih lanjut agar mampu mendukung dan memfasilitasi pengembangan dan atau peningkatan derajat intelektual sivitas akademika (untuk perpustakaan pendidikan) maupun warga masyarakat secara umum (untuk perpustakaan umum).

Kalau kita asumsikan bahwa secara manajerial perpustakaan kita sudah memasuki pada tahap ke2, maka diperlukan usaha ekstra keras agar supaya:

1. Tercipta kesadaran bahwa pustakawan bukan hanya sekedar bidang pekerjaan untuk mendapatkan gaji setiap bulan. Pustakawan harus mempunyai kesadaran "beyond economic needs". Artinya, pustakawan harus mampu menciptakan layanan terobosan (kreatif) sedemikian rupa sehingga mampu mengatasi, misalnya, keterbatasan fasilitas, keterbatan dana dan sebagainya. 
2. Tercipta kesadaran di kalangan stakeholders bahwa perpustakaan bukan hanya sekedar pusat informasi dan dokumentasi. Lebih dari itu, mereka harus dimotivasi agar memahami fungsi dan manfaat informasi bagi peningkatan harkat dan martabat mereka sebagai manusia.

3. Tercipta kesadaran di kalangan pemangku institusi bahwa perpustakaan bukan sekedar pelengkap bagi eksistensi lembaga mereka. Mereka harus memahami betul bahwa perpustakaan merupakan kunci sukses pengembangan institusi mereka.

4. Tercipta kesadaran di kalangan pemerintah bahwa perpustakaan bukan hanya sekedar untuk aktivitas pencitraan belaka. Mereka yang mempunyai "political will" yang kuat bahwa membangun dan mengembangkan perpustakaan merupakan amanah UUD 1945 dalam rangka ikut mencerdaskan bangsa.

Empat jenis kesadaran tersebut di atas merupakan prasyarat untuk membangun dan mengembangkan perpustakaan kita agar mampu mencapai "fungsi enlightment", yaitu fungsi perpustakaan yang sangat kita idam-idamkan. Untuk bisa mewujudkan cita-cita ini, menurut Du Mont (1991) diperlukan sinergi yang saling mengisi antara pustakawan, pemangku perpustakaan, pemerintah, stakeholders dan masyarakat umum, secara sistematis dan berkesinambungan. Kami percaya bahwa "empat kesadaran" tersebut bisa menjadi "gergaji” yang mampu memutus mata rantai tersebut di atas.

Mendorong pemerintah untuk berinvestasi bagi pembangunan dan pengembangan perpustakaan rupanya sangat sulit; mengharapkan warga masyarakat agar supaya lebih memanfaatkan dan menggunakan layanan perpustakaan, saat mereka membutuhkan informasi, nampaknya menghadapi banyak kendala. Masih ada secercah harapan yaitu mengelola Pustakawan dengan cara membangun etoskerja dan daya-kreatifitas yang tinggi.Pertanyaannya adalah "bagaimana membangun etos-kerja dan dayakreatifitas pustakawan dalam kondisi yang serba terbatas?” Jawabannya mengembangkan etika-moral sebagai pedoman berperilaku atau guideline bagi para pustakawan dalam menjalankan tugas dan kuajibannya.

Dengan etos-kerja dan daya-kreatifitas yang tinggi, Pustakawan diharapkan mampu mengembangkan layanan perpustakaan yang bersifat promotif-afirmatif meskipun dalam kondisi yang serba terbatas. Layanan promotif-afirmatif diharapkan menjadi magnet yang mampu menarik warga masyarakat dan stakeholders yang lain untuk memanfaatkan jasa layanan perpustakaan. Secara cerdaskreatif, pustakawan harus mampu pengelola setiap pengunjung yang datang, layaknya menjamu tamu yang datang ke rumah, buat pengunjung terkesan dan puas. Kepuasan pengunjung akan membawa dampak yang sangat positif karena mereka akan bercerita dengan temannya, tetangganya maupun koleganya. Ini akan menjadi alat dan strategi promosi yang luar biasa. Sekalipun membutuhkan waktu, namun hasilnya akan lebih mantap. Dengan demikian, jumlah pengunjung akan selalu meningkat dari hari ke hari. Peningkatan jumlah pengunjung akan menjadi instrumen yang akuntable untuk menarik perhatian pemerintah agar bersedia untuk menambah alokasi pendanaan bagi pembangunan dan pengembangan perpustakan. Pemerintah akan yakin bahwa investasinya tidak akan terbuang percuma. 


\section{Etika (Profesi) Pustakawan}

Ikatan Pustakawan Indonesia (IPI) pertama kali merumuskan Kode Etik Pustakawan Indonesia pada tahun 1993, kemudian diperbaharui lagi tahun 1997, dan akhirnya disempurnakan pada tanggal 19 September 2002 melalui Konggres IPI yang ke IX di Batu, Malang, Jawa Timur. Dengan sudah dirumuskannya Kode Etik Pustakawan Indonesia, maka kita sudah mempunyai modal awal untuk membangun dan meningkatkan profesionalisme Pustakawan Indonesia. Dikatakan demikian karena rumusan tersebut masih harus diinternalisasikan ke hati para Pustakawan agar dipahami dan dihayati sebagai pedoman berperilaku dan akhirnya menjadi way of life bagi pustakawan dalam mengemban tugas dan tanggung jawabnya.Sebagaimana ditegaskan oleh Celine (2010: 10) bahwa kode etik merupakan produk kepercayaan dan aturan yang diajarkan kepada kita sejak anak-anak dan kemudian dimantapkan setelah dewasa. Ini mengandung makna bahwa Rumusan Kode Etik Pustakawan Indonesia tersebut masih sebatas sebagai aturan berperilaku yang efektifitasnya membutuhkan internalisasi yang secara sistematis dan berkelanjutan agar supaya betul-betul tertanam di hati dan jiwa para Pustakawan Indonesia.

Setiap Pustakawan harus menjiwai dan menghayati intisari atau makna rumusan Kode Etik dimaksud sedemikian rupa sehingga setiap keputusan dan atau tindakan yang diambil merupakan cerminan dari isi dan makna Kode Etik dan dilakukan atas dasar dorongan untuk memberikan yang terbaik bagi pengunjung perpustakaan tanpa adanya unsur terpaksa.

Sebelum kita melangkah lebih jauh, tidak ada jeleknya kalau kita membangun kesepahaman mengenai apa sebenarnya yang dimaksudkan dengan etika (profesi) pustakawan dalam konteks ini. Kata etika atau ethics berasal dari bahasa Yunani yaitu etos atau "ethos" yang berarti karakter. Seseorang yang beretika adalah orang yang mempunyai karakter yang bagus yang senantiasa melakukan tindakan yang benar. Tindakan tersebut merupakan pilihan pribadi atau self-determined, bukan karena dipaksa oleh orang lain. Oleh karena itu etika merupakan tindakan sukarela yang didorong oleh kesadaran sendiri atau self-inforced (NSPA: National Scholastic Press Association: 2009).

Menurut Du Mont (1991) tujuan dari etika adalah membangun atau mengembangkan prinsipprinsip bertindak atau berperilaku untuk membantu orang memilih atau menentukan pilihan diantara sekian alternatif tindakan yang umum.

Etika berhubungan dengan hukum, akan tetapi etika berbeda dengan hukum.Hukum ditentukan dan ditegakkan secara sosial. Hukum menegaskan apa yang dapat kita lakukan, sebaliknya, etika menekankan apa yang seharusnya kita lakukan; apa yang legal belum tentu etis. Mempunyai hak atau kebebasan untuk mengatakan, mungkin tidak benar atau tidak baik untuk mengatakannya. (NSPA; 2009).

Menurut Franz Magnis-Suseno (1995:6) etika dalam arti yang sebenarnya merupakan falsafah moral. Artinya bahwa etika merupakan manifestasi moral seseorang. Selanjutnya ia menjelaskan secara lebih 
operasional bahwa etika merupakan keseluruhan norma, aturan, sopan-santun, adat-istiadat yang berlaku dalam sebuah komunitas yang mendasari perilaku keseharian para anggotanya, bagaimana mereka saling berhubungan dan berinteraksi, baik secara internal maupun eksternal. Etika merupakan sesuatu yang mendasari seseorang untuk melakukan sesuatu atau tidak melakukan sesuatu. Sedangkan moral merupakan perpaduan atau kesatuan norma yang bersifat komprehensip, ekstensip dan turun-temurun. Moral merupakan instrument atau ukuran praktis bagi perilaku orang yang tergabung dalam sebuah kelompok atau komunitas.

Sampai di sini, ditemukan dua konsep yang sebenarnya berbeda tetapi seringkali digunakan secara bergantian dengan maksud yang sama, yaitu etika dan moral. Secara konseptual, keduanya berbeda, meskipun seringkali digunakan secara bergantian sebagai sinonim. Dalam konseks ini, kami membedakan antara etika dan moral. Etika merupakan standarisasi perilaku dan tindakan, merupakan aturan tata-krama atau sopan-santun sebagai hasil kesepakatan yang seyogyanya dipatuhi, sedang moral merupakan pilihan sukarela atas dasar karakter atau kepribadian seseorang. Karena alasan inilah kami menggunakan istilah atau konsep "etika-moral”, bukan hanya etika atau moral saja.

Dalam bukunya yang berjudul Ethics in Media Communication, Louis Alvin Day (2000) menjelaskan bahwa moral berasal dari bahasa Latin mos, moris yang berarti "way of life" atau conduct, yang seringkali berkaitan dengan kepercayaan atau perilaku personal. Sedangkan etika berasal dari bahasa Yunani ethos, yang berarti custom, usage atau character, yang dikenal sebagai proses penerapan prinsipprinsip yang sudah dikembangkan atau diakui secara rasional pada saat dua atau lebih obligasi moral harus diputuskan.

Jelaslah sekarang bahwa antara etika dan moral merupakan dua konsep yang berbeda. Meskipun demikian keduanya salingterkait satu sama lain, yang satu membentuk atau mempengaruhi yang lain. Moral yang baik akan membentuk etika yang baik, sebaliknya moral yangrendah akan mempengaruhi etika yang kurang baik. Hipotesa ini selaras dengan apa yang dijelaskan oleh Vellani (2001) bahwa moral yang positif akan memudahkan terciptanya motivasi karyawan, menyemangati teamwork, menyatukan satuan kerja ke arah misi organisasi. Moral yang tinggi akan membantu terciptanya positive self-image, meningkatkan professionalisme dan ketepatan pelaksanaan tugas yang diberikan. Sebaliknya, moral yang rendah atau negatif akan mengarah pada "kurang perhatian dan pengabaian terhadap pelaksanaan tugas, yang akan membahayakan perbaikan kinerja.

Selain itu, moral yang rendah/negatif (Garland, 2002) juga akan meningkatkan keterlambatan penyelesaian tugas, berpaling dari tugas, dan ketidak-hadiran karyawan, yang pada gilirannya tidak hanya meningkatkan stress tetapi juga akan menimbulkan persoalan dalam bidang pengawasan dan supervisi administrasi. Moral yang rendah akan menurunkan performance karyawan baik di tingkat individual maupun kelompok yang selanjutnya akan meracuni organisasi secara keseluruhan.

Keterkaitan antara etika dengan moral ibarat nurani dengan nafsu. Orang dengan hati nurani yang barsih akan mampu mengendalikan nafsunya, yang tercermin pada perilaku yang baik. Etika saja tidak cukup, 
karena kepatuhan seseorang terhadap kode etik sangat tergantung pada moralitasnya. Sebaliknya, dengan moral saja juga belum memadai, karena dibutuhkan referensi untuk standarisasi profesionalisme dalam bentuk kode etik.

Fakta menunjukkan bahwa keterkaitan antara etika dengan moral adalah sangat erat. Sebagaimana dijelaskan oleh Celine (2010: 11) bahwa "ethics is described as the inner-guiding moral principles, values and beliefs that professional uses to analyse a situation and then decide the right way to behave". "Learning how to think and act" bisa dimaknai sebagai proses mempertimbangkan dalam menentukan pilihan. Artinya bahwa moral membentuk pola berfikir dan bertindak sedangkan etika menyediakan alternatif pilihan yag harus ditetapkan oleh seseorang.

Berdasarkan paparan tersebut di atas maka kami berkeyakinan bahwa pendekatan Etika-Moral lebih mampu dan lebih akuntabel dalam upaya meningkatkan profesionalisme pustakawan, utamanya pustakawan yang bekerja pada Pepustakaan Daerah atau Perpustakaan Umum.

\section{Pendekatan Etika-moral bagi Peningkatan Profesionalisme Pustakawan}

Fakta menunjukkan bahwa tidak semua yang sekarang menyandang profesi sebagai pustakawan mempunyai riwayat pendidikan formal ilmu perpustakaan. Memang sekarang sudah semakin banyak pustakawan yang menyandang gelar sarjana, pascasarjana maupun doktor ilmu perpustakaan, tetapi juga masih banyak staff yag karena sesuatu hal dipindahkan ke perpustakaan, yang kemudian menjadi pustakawan atau staff yang mengerjakan layanan perpustakaan. Ini merupakan salah satu faktor, selain faktor-faktor yang telah disebutkan di atas, yang menjadi kendala bagi upaya untuk memajukan layanan perpustakaan yang ideal.

\subsection{Internalisasi Kode Etik Pustakawan}

Menurut Celine (2010: 8-9) pustakawan merupakan profesi yang bersifat client-centered, oleh karenanya membutuhkan standards of excellence, established rules of conduct and a sense of responsibility bagi para kliennya dan masyarakat secara umum. Profesionalisme pustakawan merupakan hasil pendidikan formal, akan tetapi untuk mendapatkan kehormatan atau martabat profesional, pustakawan harus senantiasa memperbaiki dan menjaga image atau citranya. Ini merupakan alasan utama mengapa profesi sebagai pustakawan membutuhkan code of ethicsuntuk menjaga standar ekselensi melalui pengembangan rules or professional conduct. Ini mengandung makna bahwa rules or professional conduct adalah mutlak diperlukan.

Berdasarkan fakta keragaman pustakawan yang ada di daerah maka sosialisasi dan internalisasi Kode Etik Pustakawan menjadi sangat esensial. Ini didasarkan atas kenyataan bahwa pustakawan yang bekerja di Perpustakaan Umum/Daerah mempunyai latar belakang pendidikan yang beragam. Sehingga, dibutuhkan program khusus agar supaya ada jaminan bahwa setiap pustakawan mempunyai pemahaman 
yang memadai mengenai isi dan makna Kode Etik Pustakawan Indonesia. Nilai penting pemahaman ini ditegaskan oleh Valentine dan Barnett (2003) sebagai berikut: bahwa kesadaran/pemahaman pengawai (pustakawan) atas kode etik akan membawa pegawai (pustakawan) tersebut pada pemahaman mereka tentang nilai-nilai etika korporasi/institusi dimana mereka bekerja, yang pada gilirannya akan melahirkan komitmen mereka terhadap (tujuan/misi) organisasi.

Target akhir dari internalisasi adalah terciptanya komitmen di kalangan pegawai/pustakawan terhadap misi dan tujuan organisasi. Komitmen inilah yang akan melahirkan etos-kerja dan daya kreatifitas yang bersifat sukarela tanpa paksaan. Ini yang sangat dibutuhkan dalam pengembangan layanan perpustakaan dalam situasi dan kondisi yang serba terbatas.

Sebagaimana dijelaskan sebelumnya bahwa Kode Etik merupakan rumusan aturan atau rujukan berperilaku untuk menciptakan hubungan yang harmonis di antara para pustakawan, pustakawan dengan client-nya, maupun antara pustakawan dengan anggota stakeholder. Sebagaimana dijelaskan oleh Hoffman (2005) bahwa etika merupakan prinsip-prinsip bertindak atau berperilaku yang mengatur individu atau kelompok. Adapun tujuannya adalah untuk merekonstruksi perangkat organisasi sehingga mampu menggerakkan organisiasi perpustakaan agar mampu menyediakan dan mengembangkan layanan yang memadai. Melalui etika akan terjaga hubungan yang baik antara pustakawan dan para pengguna. Etika sangat penting untuk menjamin pelaksanaan tanggung jawab bagi pengembangan profesi, untuk meningkatkan excellence di antara para pustakawan, untuk memperkuat kerjasama dan koordinasi di antara para pustakawan, dan untuk membangun hubungan yang baik dengan kolega dan anggota profesi lain (Waghmare: 2013, p 19).

\subsection{Moral dan Moralitas}

Di atas sudah dijelaskan bahwa dengan kode etik saja masih belum cukup. Memahami akan isi dan makna kode etik masih belum bisa menjamin loyalitas pustakawan terhadap kode etik hasil survey yag dilakukan di Amerika terhadap 747 tenaga profesional menunjukkan bahwa 54\% diantaranya terlibat pelanggaran terhadap kode etik profesi, seperti disiplin pegawai, pelanggaran terhadap Fair Labor Standars, pelanggaran terhadap aturan kesehatan dan keselamatan kerja, bahkan tidak sedikit yang terlibat dalam kasus gratifikasi, baik dalam bentuk hadiah maupun hiburan (Schumann: 2001).

Pada institusi dimana Schumann melakukan survey, para karyawan mengetahui dan paham terhadap kode etik yang harus mereka patuhi. Namun tingkat pelanggarannya masih cukup tinggi. Ini menguatkan penjelasan sebelumnya bahwa pemahaman saja belum menjamin loyalitas para pegawai terhadap kode etik yangtelah disepakati. Artinya bahwa moral dan moralitas merupakan kunci utama loyalitas pegawai terhadap aturan dan kode etik yang berlaku. Oleh karena itu, moral harus dibina dan ditumbuh-kembangkan di kalangan pegawai.

Menurut Freeman (1999) moral positif bisa dibangun melalui fondasi organisasi. Atas dasar pernyataan ini, moral pustakawan bisa dibangun dan dikembangkan melalui pengembangan budaya organisasi yang mampu mengakomodir kepentingan dan keinginan pustakawan. Adapun kepentingan atau 
keinginan pustakawan di daerah yang berhasil kami identifikasi, diantaranya adalah, jaminan karir, jaminan kesejahteraan, penghargaan terhadap prestasi (baik secara individual maupun kelompok/tim), dan pengakuan yang layak terhadap profesi pustakawan.

Lawrence Andrew Hartman III (2003), seorang Kapten pada York County Prison di Pensylvania, mengidentifikasi 6 isu atau faktor yang bisa mempengaruhi moral karyawan, yaitu:

- Training/Pelatihan dan pendidikan

- Mission statement, prosedur, dan peranan

- Supervisi

- Pemberdayaan karyawan

- Pengakuan/recognition, feedback and commuication

- Lingkungan organisasi

Enam faktor inilah yang apabila dikelola dengan baik bisa menghasilkan moral positif di kalangan pustakawan.

Oleh karenanya, dibutuhkan model kepemimpinan dan karakter pemimpin yang mampu:

1. Mendorong pustakawan agar senantiasa meningkatkan kompetensinya baik melalui pelatihan maupun pendidikan-lanjut.

2. Memahami dengan baik visi-misi lembaga, memahami prosedur pelaksanaan tugas dan tanggung jawab, serta menyadari fungsi dan peranan masing-masing individu bagi pengembangan lembaga.

3. Memaklumi bahwa supervisi yang dilakukan oleh pimpinan bukan hanya sekedar "pengawan" atasan terhadap bawahan, akan tetapi lebih merupakan ujud tanggung jawab pimpinan terhadap kelangsungan hidup lembaga secara keseluruhan

4. Mampu memberdayakan seluruh karyawan (pustakawan) dengan memberikan tugas dan tanggung jawab sesuai dengan kapasitas dan kompetensinya.

5. Mengembangkan human relation sedemikian rupa sehingga para pustakawan merasa diakui keberadaannya, didengar pendapatnya, dihargai hasil kerjanya, diperhatikan keluhanya, dan diakomodir usulannya

6. Menciptakan lingkungan dan budaya organisasi dimana seluruh anggota organisasi perpustakaan merupakan saudara yang saling mengenal, saling menjaga, dan saling peduli satu sama lain. Mempunyai willingness yang tinggi sehingga yang satu bersedia melengkapi kelemahan atau kekurangan yang lain.

Enam kemampuan tersebut akan menghasilkan kepemimpinan yang efektif. Konsekuensi logis dari gaya kepemimpinan yang demikian akan mampu membangkitkan motivasi di kalangan pustakawan, 
selanjutnya, motivasi tinggi, baik secara langsung maupun tidak langsung, akan menjadi lahan yang subur bagi tumbuh-kembangnya moral yang positif (Freeman, 1999).

\section{Simpulan}

Simpulan yang kita peroleh dari kajian tersebut di atas adalah:

1. Perilaku etis akan meningkatkan superioritas layanan perpustakaan yang mengarah pada kepuasan pengguna jasa layanan tersebut.

2. Perilaku etis hanya bisa diwujudkan apabila pustakawan mempunyai moral dan moralitas yng tinggi.

3. Perilaku moral akan memberikan kontribusi bagi pengembangan profesi, meningkatkan citra perpustakaan dengan cara yang terhormat, dan akan mendorong masyarakat menjadi an intellectual and learning community yang akan memberikan manfaat bagi negara maupun kehidupan manusia.

4. Perilaku etis yang didasari oleh moral yang positif akan menghasilkan komitmen dan partisipasi pustakawan dalam aktifitas kelembagaan, baik secara individu maupun kelompok.

\section{Daftar Pustaka}

Day, Louis Alvin. 2000. Ethics in Media Communication, Focal Press: London, British.

Du Mont, Rosemary Ruhig. 1977. Reform and Reaction: The big city public library in American life; Aestport, CT: Greenwood Press.

Du Mont, Rosemary Ruhig. 1991. Ethics in Librarianship: A management model; Library Trends, Vol. 40, No. 2; Fall 1991, pp. 201-215

Freeman, R. M.. 1999. Correctional Organisation and Management: Public policy challenges, behavior dan structure; Boston, MA: Butterworth-Heinemann

Garland, B. 2002. Prison treatment staff burnout: Consequences, causes, and prevention; Correction Today, 64 (7) pp. $116-121$.

Hartman, Lawrence Andrew III. 2003. An Examination of Employee Morale in Correctional Institutions. http://www.ifpo.org/resource-links/articles-and-reports/protection-of-specific-environments/anexamination-of-employee-morale-in-correctional-institutions/

Hoffman, Kathy. 2005. Professional Ethics and Librarianship; Texas Library Journal; Fall, 2005 
Maluma-Mwafulilwa, Celine. 2010. Assessing the Need for a Code of Ethics for Librarians in Zambia; A disertation submited to the University of Zambian in partial fulfillment of the requirement for the degree of Master of Library and Information Science; University of Zambia, Lusaka.

National Scholastic Press Association (NSPA). 2009. Model Code of Ethics: for High School Journalists; First Edition.

Schumann; Paul L. 2001. A Moral Principles Framework for Human Resource Management Ethics; Human resource management review: 11 (2001) 93 - 111

Valentine, Sean. Barnett, Tim. 2003. Ethics Code Awereness, Perceived Vaues, and Organisational Commitment; Journal of Personal Selling \& Sales Management, Vol XXIII, N. 4 (Fall, 2003) pp Ethics359 - Ethics367.

Vellani, K. H. 2001. Don’t Let Your Guard Down; Security Management, 45 (10), 88 - 92

Waghmare, D.D. 2008. Ethic, Values and Library Professional's Behavior in ICT Environment: In social context; International Journal of Education Research and Technology; Vol. 4 [4] December 2013, pp. $18-20$. 